\title{
PROJETO DE APLICATIVO PARA DIAGNÓSTICO DA ACESSIBILIDADE ARQUITETÔNICA EM ESCOLAS
}

\author{
COSTA, Aline Couto da (1); \\ OLIVEIRA, Larissa Santos (2); \\ AMORIM, Felipe Ribeiro Gomes (3); \\ SANTANA, Mariana Paraguassú Caetano (4). \\ (1) IFFLUMINENSE, Doutora em Arquitetura (PROARQ/FAU/UFRJ) \\ e-mail: acosta@iff.edu.br \\ (2) IFFLUMINENSE, Graduanda em Arquitetura e Urbanismo \\ e-mail: larissantos713@gmail.com \\ (3) IFFLUMINENSE, Graduando em Engenharia de Controle e Automação, \\ e-mail: frgamorim@gmail.com \\ (4) IFFLUMINENSE, Graduanda em Arquitetura e Urbanismo \\ e-mail: mariparaguassu.arq@gmail.com
}

\begin{abstract}
RESUMO
A urgência em prover acessibilidade nas escolas demanda atenção ao tema, fazendo com que os responsáveis por esses espaços realizem diagnósticos para a solução dos problemas. Esse levantamento pode ser auxiliado pela ferramenta do checklist, desenvolvida por alguns pesquisadores. Entretanto, há a necessidade de atualização desse instrumento de acordo com as normas recentes de acessibilidade; além da possibilidade de desenvolvê-lo através de um aplicativo, para facilitar a realização da tarefa, bem como a sistematização de dados. Assim, o objetivo do trabalho consiste em apresentar o projeto de desenvolvimento de um aplicativo para diagnóstico da acessibilidade arquitetônica das escolas.
\end{abstract}

Palavras chave: acessibilidade nas escolas; aplicativo de acessibilidade; arquitetura acessível.

\begin{abstract}
The urgency to provide accessibility in schools demands attention to the theme, making those responsible for these spaces diagnose problems. This survey can be aided by the checklist tool, developed by some researchers. However, there is a need to update this instrument in accordance with recent standards of accessibility; besides the possibility to develop it through an application, to facilitate the accomplishment of the task, as well as the systematization of data. Thus, the objective of this work is to present the project to develop an application to diagnose the architectural accessibility of schools.
\end{abstract}

Keywords: accessibility at school; accessibility program; accessible architecture.

\section{O PROJETO DO APLICATIVO}

Atualmente, a obrigatoriedade e a urgência em prover acessibilidade nas escolas, motivadas pela solicitação de órgãos fiscalizadores e pelo número crescente de estudantes com deficiência nos ambientes de ensino e aprendizagem, têm demandado uma atenção maior 


\section{remex $^{2}$}

ao tema. Assim, os responsáveis pelas escolas e seus espaços precisam realizar diagnósticos das condições de acessibilidade dos edifícios para a respectiva solução dos problemas.

Esse tipo de levantamento pode ser auxiliado pela ferramenta do checklist, ou lista de checagem, que se refere a um método empírico, utilizado para averiguar uma relação de elementos ou procedimentos que são previamente elencados como critérios a serem observados ou avaliados em uma pesquisa (RHEINGANTZ, 2009).

Alguns pesquisadores já desenvolveram a ferramenta do checklist, voltado às condições gerais de acessibilidade, como Guimarães e Fernandino (2001); Cohen e Duarte (2006; 2013); e também com enfoque escolar, apresentado por Dischinger, Ely e Borges (2009). Entretanto, novas regulamentações em relação ao tema da acessibilidade, como a edição da Norma Brasileira da Acessibilidade (NBR 9050/2015) e a Lei Brasileira de Inclusão da Pessoa com Deficiência (Lei no 13.146/2015), dentre outras, fazem com que haja a necessidade de elaboração de um checklist mais atualizado, inclusive direcionado à arquitetura escolar e suas particularidades.

Além disso, com a evolução da tecnologia da informação e comunicação, há a possibilidade de desenvolver essa ferramenta através de um aplicativo, a fim de facilitar o acesso e a realização do checklist, bem como a sistematização dos dados obtidos por ele. Assim, a atualização das informações também pode ser feita de modo mais dinâmico.

Acredita-se que o aplicativo para diagnóstico da acessibilidade arquitetônica em escolas possa contribuir para o trabalho de estudantes e profissionais da Arquitetura e Construção Civil, e também da área educacional, que precisam realizar levantamentos atualizados das condições de acessibilidade nos ambientes construídos institucionais, para a realização de um plano de ação em prol de uma arquitetura escolar inclusiva.

Para tanto, o objetivo geral do trabalho consiste em apresentar o projeto de desenvolvimento de um aplicativo com checklist para diagnóstico da acessibilidade arquitetônica em edifícios escolares, de acordo com as leis e normas sobre o tema, possibilitando a obtenção de um panorama da situação para a tomada de decisões quanto à solução dos problemas e consequente produção de escolas acessíveis e inclusivas.

Para atingir o objetivo geral, tem-se trabalhado os seguintes objetivos específicos: a) compreender o tema da acessibilidade arquitetônica, com enfoque em ambientes construídos escolares; b) pesquisar e sistematizar dados de leis e normas atuais relacionadas à acessibilidade arquitetônica em escolas; c) produzir tabelas com perguntas que representem os dados a serem levantados; d) estudar e selecionar a tecnologia a ser utilizada de acordo com as necessidades do aplicativo; e) transpor as informações das tabelas para uma plataforma que possibilite o desenvolvimento do aplicativo; f) estudar a ilustração visual do aplicativo e as configurações que o tornem acessível; g) realizar testes de aplicação, assim como revisões da ferramenta; $h$ ) promover ou participar de eventos que possibilitem a troca de informações referentes aos temas envolvidos na pesquisa e às necessidades do público-alvo desse projeto.

A metodologia do trabalho abrange as seguintes etapas: a) estudo sobre o tema, a partir de pesquisa bibliográfica através de publicações como: livros, artigos etc.; b) pesquisa documental com o levantamento das leis e normativas atuais relacionadas ao tema; c) sistematização das informações por assuntos e/ou partes que compõem uma arquitetura; d) produção de tabelas com perguntas que representem os dados a serem levantados de acordo com cada tema, caracterizando o checklist; e) estudos, treinos e testes das tecnologias possíveis para a realização do aplicativo; f) transposição de dados para a plataforma tecnológica que possibilite o desenvolvimento do aplicativo e o torne acessível; g) realização de testes de aplicação. 


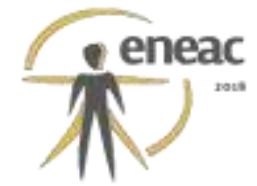

\section{O DESENVOLVIMENTO DO PROJETO}

O desenvolvimento desse projeto iniciou-se em agosto de 2017, com a leitura de normas, dentre elas, a NBR 9050/2015, assim como de alguns manuais que tem o seu conteúdo direcionado à acessibilidade em escolas.

Após esse estudo, foi possível criar uma tabela, contendo perguntas do checklist organizadas em cinco itens relacionados aos ambientes arquitetônicos da escola: a) entorno; b) acessos e estacionamentos; c) circulação; d) ambientes; e) informações e sinalizações. A sequência em que se encontram os tópicos corresponde à ordem em que pode ser feito o diagnóstico, começando pelo entorno - por ser a parte externa da escola - e depois seguindo para as demais ambiências. No entanto, é importante ressaltar que se trata de uma sugestão, já que o aplicativo não será "engessado", havendo a possibilidade de o usuário escolher a ordem em que prefere fazer o diagnóstico.

Em paralelo à elaboração das perguntas do diagnóstico, o aplicativo tem sido programado. O software utilizado foi o Xamarin, que é uma plataforma de desenvolvimento de aplicativos móveis para criar nativos iOS, Android e Windows, que são os principais sistemas operacionais existentes. A linguagem utilizada é C\# e do .NET Framework. O projeto segue em andamento, com enfoque no desenvolvimento do aplicativo no software e todas as suas implicações.

\section{PERSPECTIVAS E DESAFIOS DO PROJETO}

Acredita-se que a realização desse projeto possa auxiliar o trabalho dos responsáveis pela acessibilidade nas escolas e, acima de tudo, contribuir para a promoção de ambientes escolares acessíveis. Entretanto, muitos são os desafios envolvidos. Um deles refere-se à necessidade de a própria ferramenta ser acessível; por isso, tem-se pesquisado formas, cores, diagramação, recursos de programação etc. para que esse objetivo seja alcançado.

\section{REFERÊNCIAS BIBLIOGRÁFICAS}

ASSOCIAÇÃO BRASILEIRA DE NORMAS TÉCNICAS (ABNT). NBR 9050/2015, Acessibilidade a edificações, espaço, mobiliário e equipamentos urbanos. Rio de Janeiro: ABNT, 2015.

BRASIL. Lei no. 13.146, de 06 de julho de 2015. Institui a Lei Brasileira de Inclusão da Pessoa com Deficiência (Estatuto da Pessoa com Deficiência). Brasília, DF, 07 jul. 2015b. Portal do Planalto. Disponível em: < http://www.planalto.gov.br>. Acesso em: 14 abr. 2017.

COHEN, R.; DUARTE, Cristiane R. S. Proposta de Metodologia de Avaliação da Acessibilidade aos Espaços de Ensino Fundamental. Cadernos do PROARQ (UFRJ), v. 10, p. 129-136, 2006.

Subsídios metodológicos na construção de uma "acessibilide plena": a produção da identidade e da subjetividade de pessoas com deficiência. Revista Benjamin Constant, Rio de Janeiro, Edição Especial 03, Outubro de 2013.

DISCHINGER, Marta; ELY, V. H. M. B; BORGES, Monna M. F. da C.. Manual de acessiblidade espacial para escolas: o direito à escola acessível. Brasília: Ministério da Educação, 2009.

GUIMARÃES, M. P. e FERNANDINO, Sandra Fagundes. Coletânea de Critérios para a Acessibilidade. Projeto Escala Gradativa da Acessibilidade, fomentado pela CORDE/Ministério da Justiça. ADAPTSE EA UFMG, abril de 2001.

RHEINGANTZ, Paulo et al. Observando a qualidade do Lugar: procedimentos para avaliação pósocupação. Rio de Janeiro: PROARQ, 2009. Disponível em: <http://www.fau.ufrj.br/prolugar/ arq_pdf/livros/obs_a_qua_lugar.pdf>. Acesso em: 15 mar. 2017. 